\title{
Akuntabilitas Sistem Informasi Manajemen Kearsipan dan E-Dokumen
}

\author{
Jarkawi', Riadhul Muttaqin ${ }^{2}$ \\ Universitas Islam Kalimantan Muhammad Arsyad Al Banjari \\ jarkawi010462@gmail.com, aqin.060610448@gmail.com
}

\begin{abstract}
Archival accountability as a public service in meeting stakeholders and study material for managers in making decisions. Archival activities and e-documents on an agency is a sub-system of a government system that is constantly changing and developing so that changes and developments affect the institution as a sub-system where the sub-systems interact between subsystems in the system itself. In the future, archives and e-documents will use an electronic system because it is very effective and efficient, critical, outcomes in an activity a manager takes a decision and policy. The problem still uses a lot of document archiving manually so that it takes a long time to find archives that have an impact on activities to be less effective and less efficient. The purpose of providing electronic skills competencies in e-documents. The form of activities carried out in the form of training and workshop management system for e-documents. The benefits of this activity provide a competence in knowledge and skills in managing archives through electronic (e-documents) so that organizational activities become effective efficiently productive and outcomes. Target audiences are kindergarten and paud teachers located in Mandastana subdistrict, Barito Kuala district. Implementation Method. Training and Workshop, Discussion and Questions and Answers. Results Training and workshop participants get new insights and skills in e-documents.
\end{abstract}

Keywords: Accountability; Management Information Systems; Archives; E-Documents

\begin{abstract}
Abstrak
Akuntabilitas kearsipan sebagai pelayanan publik dalam memenuhi stakeholder dan bahan kajian bagi manejer dalam mengambil keputusan. Kegiatan kearsipan dan e-dokumen pada suatu instansi merupakan sub sistem dari suatu sistem pemerintahan yang terus berubah dan berkembang sehingga perubahan dan perkembangan tersebut mempengahui isntansi sebagai sub sistem dimana sub sistem saling berinteraksi antar sub sistem dalam suatu sistem itu sendiri. Kedepannya kearsipan dan e-dokumen akan menggunakan sistem eletronik karena sangat efektif dan efisien, kriatif, outcome dalam suatu aktivitas seorang manejer mengambil suatu keputusan dan kebijakan. Permasalahan masih banyak menggunakan kearsipan dokumen dengan manual sehingga memakan waktu lama dalam mencari arsip yang berdampak terhadap kegiatan menjadi kurang efekti dan kurang efisien. Tujuan memberikan kompetensi ketrampilan elektronik dalam e-dokumen. Bentuk kegiatan yang dilakukan berupa pelatihan dan workshop manajemen sistem kearsipan edokumen.Manfaat kegiatan ini memberikan suatu kompetensi pengetahuan dan ketrampilan dalam pengelolaaan kearsipan melalaui elektronik (e-dokumen) agar kegiatan oragnisasi menjadi efektif efisien produktif dan outcome. Khalayak sasaran adalah guru TK dan Paud yang berada di kecamatan Mandastana Kabupaten Barito Kuala. Metode Pelaksanaan. Pelatihan dan Workshop, Diskusi dan Tanya Jawab. Hasil Peserta pelatihan dan workshop mendapatkan wawasan dan ketrampilan baru dalam e-dokumen.
\end{abstract}

Kata kunci: Akuntabilitas; Sistem Informasi Manajemen; Arsip; E-Dokumen. 


\section{A. PENDAHULUAN}

Dokumen adalah sehelai kertas atau lebih yang digunakan untuk mengadakan komunikasi sebagai bukti terjadi komonikasi. Sampai sekarang dokumen memiliki kelebihan dibandingkan dengan sarana komunikasi lainnya, kelebihannya antara lain yaitu dokumen lebih praktis karena sarana komunikasi yang dapat menyimpan rahasia dan memuat informasi. Dokumen lebih efektif karena informasi yang disampaikan sesuai dengan sumber aslinya. Dokumen dikatakan ekonomis dilihat dari biaya pembuatan dan pengiriman relatif murah.Salah satu peranan pengelolan dokumen bagi organisasi adalah dengan melakukan kegiatan pengurusan dokumen baik itu surat masuk maupun surat keluar.Faktor lain dari keberhasilan suatu manajemen juga dipengaruhi oleh sarana dan prasarana yang digunakan untuk menyimpan arsip dan efisiensi pemakaian peralatan tersebut dalam bentuk dokumen.

Demikian halnya pada bagian kelurahan Mandastana Kabupaten Baritu Kuala berfungsi sebagai penunjang kelancaran pelaksanaan komunikasi bagi pimpinan dalam membuat atau mengambil suatu keputusan secara tepat cepat dan akurat dalam mengambil kebijakan untuk mengatasi suatu masalah. Semua itu tergantung kepada kecepatan dan ketepatan informasi yang terkandung di dokumen, sistem pengelolaan dokumen diarahkan sesuai dengan kegunaan bagi kepentingan petugas pengelola dalam memaknainya. Pengelolaan dokumen pada bagian Kelurahan Mandastana sangat diperlukan manajemen sistem dokumen.
Yang baik dan benar agar kegiatan organisasi menjadi efektif, efisien, kriatif, produktif dan outcome

Untuk efektif, efisien, kriatif, produktif dan outcome organisasi pada kelurahan Mandastana kabupaten Barito Kuala diperlukan suatu pendampingan dan pembimbingan dalam pengeloalaan dokumen dengan tujuan agar setiap pemipin akan mudah mengambil kebijakan secara tepat dan akurat sesuai kebutuhan organisasi dan stakeholder dalam bentuk kegiatan Workshop

\section{B. PELAKSAAAN DAN METODE}

Kegiatan pengabdian ini dilakukan dengan metode Workshop dan Pelatihan terhadap sejumlah personil pada kantor desa Mndastana, guru taman kanak-kanak dan guru pendidikan anak usia dini di desa Mandastana Kabupaten Barito Kuala mulai bulan Juli sampai dengan Desember 2017 berjumlah 20 orang dan terakhir kegiatan dilakukan evaluasi dan respon peserta Workshop dan Pelatihan

\section{HASIL DAN PEMBAHASAN}

\section{Akuntabilitas Kearsipan dan E-Dokumen}

Setiap instansi pemerintah mapun swasta dituntut untuk melakukan kearsipan dan e-dokumen dengan baik dan tertata rapi, bahkan tidak saja penataan dan kerapiannya, namun juga prosudur dalam melakukan kearsipan dan e-dokumen benar-benar dilaksanakan dengan baik, sehingga suatu instansi tersebut kegiatan atau aktifitasnya berupa kinerja menjadi efektif dan efisien 
serta terukur waktunya dan terindeks. Indeks inilah yang akan dijadikan penilaian akontabilitas aktivitas kearsipan dan edokumen. Dwi Afriyant, Harpanto Guno Sabanu, dan Fahrizal Noor. (2015) dapat dijelaskan bahwa diperlukan sistem indeks yang dapat menilai tingkat akuntabilitas suatu instansi.

Kegiatan kearsipan dan e-dokumen masih bersifat sederhana dan personil dari instansi belum terampil serta masih parsial dalam menata arsip dan e-dokumen karena belum sepenuhnya didesain suatu strategi kearsipan dan e-dokumen, pada hal ini merupakan suatu akontabilitas publik untuk suatu pelayanan prima bagi suatu instansi pemerintah maupun swasta kepada masyarakat, akibatnya kegiatan suatu instansi menjadi kurang efektif dan lemah kriatif serta lemah produktivitas dari suatu hasil kinerja personil dalam suatu instansi. Teguh Kurniawan. (2009)dapat dimaknai bahwa upaya yang dilakukan dalam mengatsi masalah cenderung parsial dan tidak memiliki desain strategi yang jelas sehingga banyak hal tidak mampu mengurangi secara signikan masalah yang terjadi dalam penyelenggaraan pemerintahan baik di pusat maupun daerah.

Agar akontabilitas kearsipan dan edokumen suatu instansi dari suatu hasil kinerja personil dalam suatu instansi perlu suatu perencanaan strategis dari suatu instansi dan bertanggung jawab terhadap pengelolaan kearsipan dan e-dokumen. Ismanudin. (2012).Dapat ditegaskan dengan diterbitkannnya Instruksi Presiden (Inpres) RI Nomor 7 Tahun 1999 tentang Akuntabilitas Kinerja Instansi Pemerintah
(AKIP) mewajibkan kepada setiap instansi pemerintah sebagai unsur penyelenggara pemerintahan negara bertanggungjawab atas pelaksanaan tugas pokok, dan fungsinya, serta kewenangan pengelolaan dengan didasarkanpada suatu perencanaan strategik yang ditetapkan oleh masing- masing instansipemerintah.

Dengan akontabiltas kinerja personil dalam suatu instansi dapat menciptakan kepercayaan masyarakat dan profesionalisme personil pada bagian kearsipan dan edokumen. Nurul Huda. Desti Anggraini. Nova Rini Hudori, Yosi Mardoni (2014) dapat dimaknai peningkatan akuntabilitas pengelolaan akan membentuk profesionalitas pengelolaan dan dapat meningkatkan kepercayaan masyarakat. Akontabilitas juga berpengaruh terhadap kinerja. Lucy Auditya.(2013)dapat dijelaskan bahwa akuntabilitas pengelolaan berpengaruh positif dan signifikan terhadap kinerja pemerintah

Dalam menciptakan akontabilitas kearsipan dan e-dokumen di Kantor desa Mandastana diberikan workshop dan pelatihan sistem informasi manajemen kearsipan dan e-dokumen alur sistem kegiatan kearsipan dan e- dokumen, apaila tidak jelas asistem dan alur kegiatan kearsipan dan e-dokumen maka pengelolaan kearsipan menjadi tidak jelas. Davis Budi Purnama1, Hendy Widiastoeti. (2016)dapat dimaknai bahwa tidak adanya sistem informasi pengelolaan yang jelas sehingga tidak ada informasi yang jelas di dalam proses pengelolaan. Untuk itu agar pengelolaan kearsipan dan e-dokumen jelas dapat dilihat sebagai berikut: 


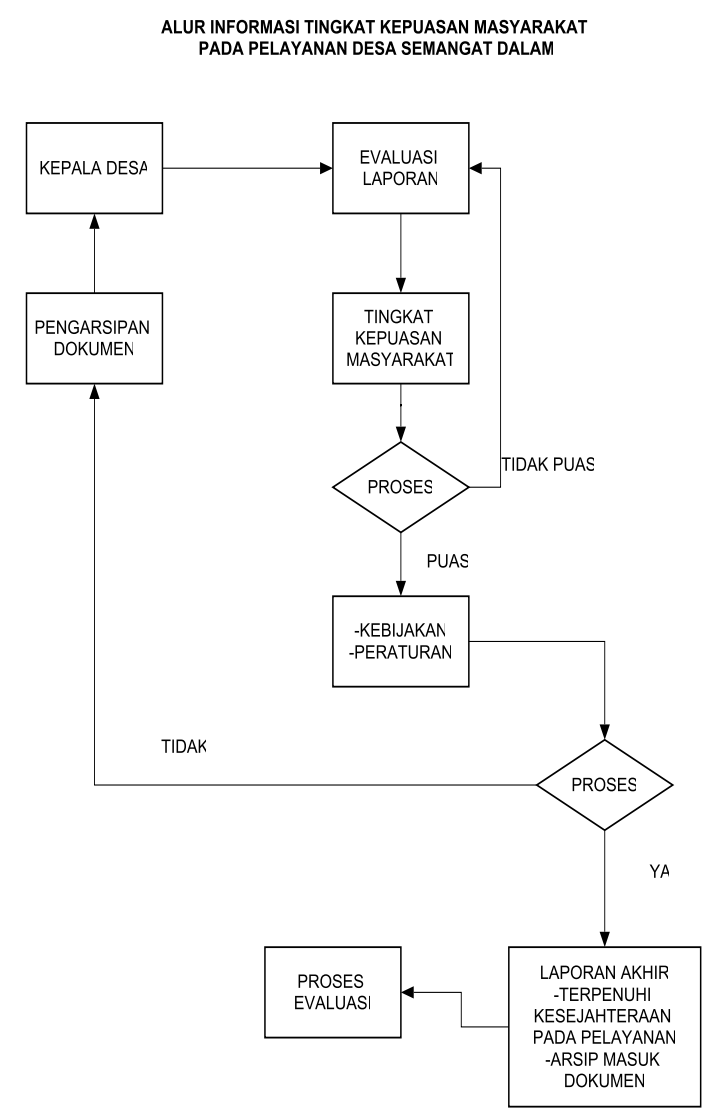

Gambar 1. Flowchart Alur Informasi tingkat Kepuasan Stikeholder

Alur informasi tingkat kepuasan pelayanan kantor desa terhadap masyarakat desa yang akan diterapkan oleh perangkat desa dengan capaian tingkat kepuasan selanjutnya kepala desa akan menerapkan sebagai kebijakan dan dijadikan peraturan desa dengan kepuasan tingkat pelayanan kepada masysrakat desa dan sebagai terpenuhinya kesejahteraan masyarakat desa pada pelayanan yang akan dijadikan arsip atau dokumen desa yang sebagai data masyarakat untuk kepala desa dan jikalau proses pelayanan pada masyarakat merasa tidak puas selanjutnya akan dievaluasi oleh kepala desa untuk dibenahi oleh semua perangkat desa.

\section{Sistem Manajemen Kearsipan dan E- Dokumen}

Sisttem manajemen kearsipan dan edokumen merupakan suatu kegiatan pengelolaan yang saling berkaitan antar sub komponen dengan sub kmponen lainnya dalam rangka mencapai suatu tujuan instansi secara efektif dan efisien yang sipatnya memori kolektif yang ada pada suatu instansi, sehingga kinerja kinerja bagian kearsipan lembaga dari waktu ke waktu dapat diketahui dan sebagai suatu prestasi kinerja bagi instansi tersebut. Susiasih Damalita. (2009)dapat dimaknai bahwa Kesimpulan arsip yang tertata rapi akan menjadi bukti prestasi yang dicapai.

Menghadapi era digital kedepan dalam manajemen kearsipan dan e-dokumen akan berbasis informasi dan teknologi, maka instansi sejak sekarang sudah mempersiapkan personil yang terampil dan ahli dalam bidang informasi teknologi di instansinya. Machsun Rifauddin (2016) dapat dijelaskan bahwa arsip elektronik merupakan arsip jenis baru dengan perpaduan teknologi informasi sebagai media pengelolaannya dan melalui pengelolaan arsip elektronik lebih evektif dan efivisien dibandingkan dengan arsip cetak dan dalam pengarsipannya tidak banyak membutukan tempat cukup dengan hardisk, CD, DVD. Lebih tegas lagi disebutkan juga dari aspek hukum bahwa arsip elektronik memiliki nilai sama dengan arsip cetak yang diakui sebagai alat bukti hukum yang sah sesuai Undang- Undang Nomor 11 Tahun 2008 tentang Informasi dan Transaksi Elektronik.

Kearsiapan dan e-dokumen dengan sistem informasi pengelolaan berbasis 
aplikasi Delphi 7 dengan menggunakan data base Ms.Acces yang dilakukan di desa Semangat Dalam Kabupaten Barito Kuala. Sistem manajemen kearsipan dan e-dokumen dapat dilihat sebagaimana Gambar 2.

ALUR INFORMASI PENGARSIPAN DOKUMEN DESA SEMANGAT DALAM

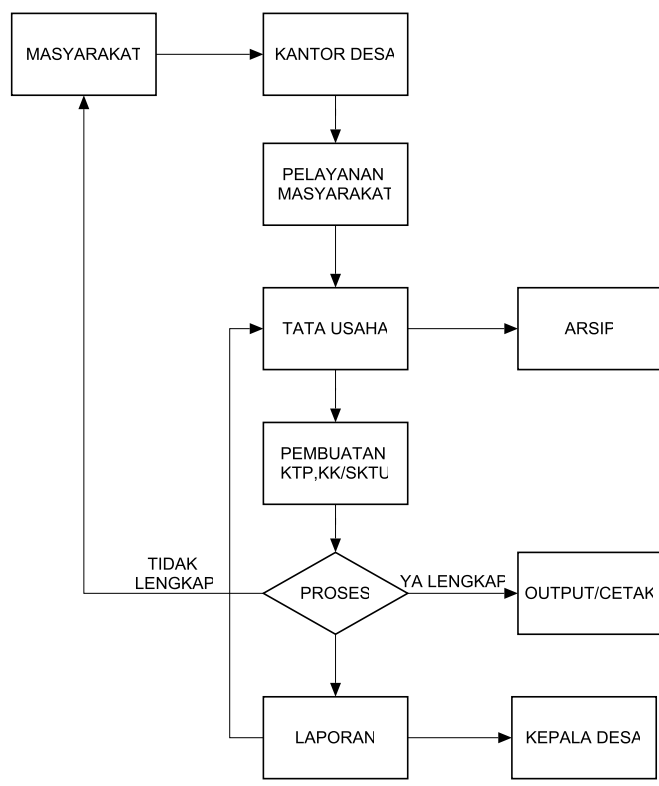

Gambar 2. Flowchart Alur Kegiatan Kearsipan dan edokumen

Alur informasi flow chart tersebut diatas menjelaskan masyarakat desa akan membuat identitas ke kantor desa yang dilaksanakan oleh pelayanan masysrakat desa oleh perangkat desa yang dikerjakan oleh administasi tata usaha, apa yang harus dikerjakan sesuai dengan permintaan masyarakat desa seperti: KTP, KK, SKTU, Surat Ijin Nikah yang harus diproses sesuai dengan kelengkapan persyaratan. Proses lengkap akan dicetak dan dilaporkan ke kepala Desa dan akan dimasukkan sebagai dokumen untuk diarsipkan, kalau persyaratan tidak lengkap maka data akan dikembalikan untuk dilengkapi.Begitu juga untuk para guru berkaiatan dengan kearsipan surat keterangan dan untuk berbagai pengarsipan laporan sekolah baik secara internal sekolah maupun eksternal sekolah (Unit pelaksanaa teknis) yang ada di Kecamatan Alalak dan Dinas Pendidikan Kabupaten Barito Kuala.

\section{PENUTUP}

\section{Kesimpulan}

Masyarakat merasakan manfaat dari kegiatan pelatihan dan workshop manajemen sistem kearsipan e-dokumen dengan penambahan dan peningkatan kompetensi pengetahuan dan ketrampilan dalam pengelolaaan kearsipan melalaui elektronik (e-dokumen), ini dibuktikan dari hasil evaluasi selama proses (melalui diskusi dan tanya jawab) dan akhir pelaksanaan melalui hasil angket kepuasaan peserta.

\section{Saran}

Kepada kepala desa agar menggunakan sistem kearsipan e-dokumen sehingga memudahkan dalam mengambil kebijakan dan keputusan dalam memajukan warga desanya. Untuk warga desa perlu kesadarannya bahwa melalui sistem kearsipan e-dokumen akan membantu cepatnya proses pelayanan yang memuaskan.

\section{E. DAFTAR PUSTAKA}

Afriyanto, D.S, Harpanto Guno. Noor, Fahrizal. 2015. Accountability Index Assessment of Government Agencies. Jurnal Tata Kelola \& Akuntabilitas Keuangan Negara. Volume 1, Nomor 1, Juli 2015: 21-42 
Anwar Prabu Mangkunegara, 2004. Manajemen Sumber Daya Manusia, Remaja Rosdakarya, Bandung.

Alex S. Nitisemito, 2000. Manajemen Personalia: Manajemen Sumber Daya Manusia, Ed. 3, Ghalia Indonesia, Jakarta.

Amsyah, Zulkifli. 2005, Manajemen

Kearsipan. Jakarta: PT. Gramedia

PustakaUtama

Anwar Prabu Mangkunegara, 2004. Manajemen Sumber Daya Manusia, Remaja Rosdakarya, Bandung.

Arbie. 2003. Manajemen Database Dengan

MySQL. Yogyakarta: Andi

Arikunto, Suharsimi. 2002, Prosedur Penelitian Suatu Pembahasan. Jakarta: Bhineka Cipta

Barthos, Basir. 2005, Manajemen Kearsipan. Jakarta: Bumi Aksara

Eko,Indriyawan. 2006. Pemrograman Database. Yogyakarta: Andi

Haer,Talib. 2014. Panduan Lengkap MS Access 2013. Jakarta: Penerbit Elex Media Komputindo

Jimmy,Chr. Gaol,L 2008. Sistem Informasi Manajemen. Jakarta: Grasindo

Kadir, Abdul. 2003. Pengenalan Sistem Informasi. Yogyakarta: Andi

Kusnassriyanto. 2012. Belajar Pemrograman Delphi.Yogyakarta: Penerbit Informatika
Mita. 2010. Pengenalan Borland Delphi 7. Semarang.

Mulyono, Sularso, dkk. 1985, Dasar- Dasar Kearsipan. Yogyakarta: Liberty

Peraturan Pemerintah Nomor 84 Tahun 2000 tentang pedoman organisasi perangkat daerah.

Silmi, Sikka Mutiara. 2004, Panduan Menulis Surat Lengkap. Yogyakarta: Absolut

Sugiarto, Agus, dkk. 2005, Manajemen Kearsipan Modern. Yogyakarta: Gava Media

Sutarto. 1992, Sekretaris Dan Tata Warkat. Yogyakarta: Gajah Mada Universitas Press

Suwarno,Nono. 2014. Artikel Sistem Informasi Pengolahan Surat Masuk Dan Surat Keluar. Bandung.

Syamsi, Ibnu. 1994, Sistem dan Prosedur Kerja. Jakarta: Bumi Aksara

Witarto, 2004. Memahami Sistem Informasi. Bandung.

Wursanto, Ignatius. 2003, Kearsipan I. Yogyakarta : Kanisius

Kurniawan. Teguh.2009. Peranan Akuntabilitas Publik dan Partisipasi Masyarakatdalam Pemberantasan Korupsi di Pemerintahan. Bisnis \& Birokrasi, Jurnal Ilmu Administrasi dan Organisasi, Mei-Agust.us 
2009, Volume 16, Nomor 2. ISSN 0854-3844 hlm. 116-121

Nurul Huda. Desti Anggraini. Nova Rini Hudori, Yosi Mardoni Akuntabilitas Sebagai Sebuah Solusi Pengelolaan Wakaf. Jurnal Akuntansi Multiparadigma, Volume 5, Nomor 3, Desember 2014, Hlm. 485-497

Lucy Auditya. 2013HusainiLismawati. 2013. Analisis Pengaruh Akuntabilitas Dan Transparansi Pengelolaan Keuangan Daerah terhadap Kinerja pemerintah Daerah. Jurnal Fairness ISSN 23030348. Volume 3, Nomor 1, Maret 2013

Rifauddin, Machsun 2016. Pengelolaan Arsip Elektronik Berbasis Teknologi. Jurnal Khizanah AlHikmah Vol. 4 No. 2, Juli Desember 2016 Hl 168-178.

Damalita, Susiasih. 2009. Pentingnya Manajemen Arsip di Lingkungan Perguruan Tinggi. Jurnal Ekonomi, Manajemen dan Bisnis (EMAS) FE Unimas Mojokerto, Vol. 3 no. 1, Desember 2009 - ISSN 1978-7146

Davis Budi Purnama1, Hendy Widiastoeti. 2016. Audit Internal Sistem Informasi Akuntansi Pengelolaan Alokasidana Desa (Add) Untuk Menilai Akuntabilitas Kinerja Desa (Di Desa Batokan Kecamatan Kasiman Kabupaten Bojonegoro) Tahun 2015.Jurnal Ekonomi \&
Bisnis, Volume 1, Nomor 1, Maret 2016. Hal 75 - 94

Zulhalim. 2013. Desain dan Implementasi Aplikasi Alih Media Arsip Statis Menggunakan Visual Basic. Net, Sql Server dan Crystal Report Studi Kasus: Sistem Informasi Manajemen Arsip Plus Di Badan Perpustakaan Arsip Daerah Propinsi Dki Jakarta. Jurnal Manajemen Informatika. Edisi: No.4 Tahun VI / Januari 2013. Sekolah Tinggi Manajemen Informatika dan Komputer Jayakarta hal 1-10

Basri. Devitra, Joni 2017. Analisis Dan Perancangan Sistem Informasi Pengelolaan Arsip Berbasis Web (Studi Kasus: Pada Komisi Pemilihan Umum (KPU) Kabupaten Tebo). Jurnal Manajemen Sistem Informasi Vol.2, No.1, Maret 2017, DOI:

http://dx.doi.org/10.11591/jurnalmsi .v12i4.xxxx hal 227-243

Rachmaji, Achmad Syarif 2016, Peran Akuisisi Arsip Statis Bumn Terhadap Khazanah Arsip Statis Bumn Di Indonesia The Role Of Bumn's Archives Acquisition Toward Bumn's Archives Collection In Indonesia. Jurnal ANRI 2016 VOL 11/ANRI/12/2016 Hal 1-15

Handoyo. Saputra1. Pradana,Fajar. Priyambadha, Bayu. 2017. Pengembangan Elektronik Sistem Akuntabilitas Kinerja Instansi Pemerintah untuk Dinas 
Perindustrian Kota Malang. Jurnal Pengembangan Teknologi Informasi dan Ilmu Komputer e-ISSN: 2548964XVol. 1, No. 10, Oktober 2017, hlm. 1167-1175

Dedy Hernawan. 2004. Akuntabilitas Ngo dan Kontrol Publik. Jurnal Administrasi Publik, Vol.3, No.2, 2004 hal 158-169

Basri. Devitra, Joni. 2017, Analisis Dan Perancangan Sistem Informasi Pengelolaan Arsip Berbasis Web (Studi Kasus: Pada Komisi Pemilihan Umum (KPU) Kabupaten Tebo) Basri1, Joni Devitra2. Jurnal Manajemen Sistem Informasi Vol.2, No.1, Maret 2017, DOI: http://dx.doi.org/10.11591/jurnalmsi. v12i4.xxxx

Handoyo Saputra1, Fajar Pradana2, Bayu Priyambadha. 2017. Pengembangan Elektronik-Sistem Akuntabilitas Kinerja InstansiPemerintah untuk Dinas Perindustrian Kota Malang. urnal Pengembangan Teknologi Informasi dan Ilmu Komputer eISSN: 2548-964XVol. 1, No. 10, Oktober 2017, hlm. 1167-1175 http://j-ptiik.ub.ac.id

Muslimin1, Mappamiring2, St. Nurmaeta 2012 Akuntabilitas Pengelolaan Alokasi Danadesa Di Desa Punagaya Kecamatan Bangkalan Kabupaten Jeneponto. Jurnal Ilmu Pemerintahan. Vol. II No. 1 April 2012
Ismanudin. 2012. Perencanaan Strategis dalam Sistem Akuntabilitas Kinerjainstansi Pemerintah. Jurnal Aspirasi Vol. 2 No.2 Februari 2012. ISSN 2087-2208. Hal 3-10 